\title{
LX. On the existence of salts of potash in brine- springs and in rock-salt
}

\section{E.W. Brayley Jun. A.L.S.}

To cite this article: E.W. Brayley Jun. A.L.S. (1829) LX. On the existence of salts of potash in brine-springs and in rock-salt , Philosophical Magazine Series 2, 5:30, 411-416, DOI: 10.1080/14786442908675035

To link to this article: http://dx.doi.org/10.1080/14786442908675035

册 Published online: 10 Jul 2009.

Submit your article to this journal $[\pi$

Џ Article views: 2

Q View related articles $\asymp$ 


\section{[ 411$]$}

LX. On the Existence of Salts of Potash in Brine-Springs and in Rock-Salt. By E. W. Brayley, Jun., A.L.S.

$\mathbf{W}^{\mathrm{n}}$ HEN Dr. Marcet commenced his chemical examination of specimens of sea-water from various parts of the globe, the results of which are given in a paper published in the Philosophical Transactions for 1819, the probability that the waters of the ocean contain potash, " as an ingredient brought down by rivers from.the decay of land-plants," was suggested to him by Dr. Wollaston. This suggestion, as is recorded in the same paper, was verified by Dr. Wollaston himself; who thought it probable, further, that potash existed in sea-water in the state of sulphate. The last production of the former chemist, published in the Phil. Trans. for 1822, (Phil. Mag.vol. lx.) consists of some researches on the less obvious contents of seawater; proving the existence in it of a triple sulphate of potash and magnesia, and showing also that it contains an additional proportion of potash, probably in the state of muriate.

It has not appeared, hitherto, whether any chemist, in consequence of these researches, has subjected to experiment any of the varieties of rock-salt, or of brine from salt-springs, with the view of ascertaining whether they contain potash. No indication of it is recorded to have been found, in Dr. Henry's analyses of the Cheshire rock-salt and evaporated brine, or in Mr. L. Horner's analysis of the brine from the springs of Droitwich in Worcestershire. In the last Number of the Phil. Mag. and Annals, however, Dr. Bigsby, in his Sketch of the Geology of Lake Ontario, has given (at p. 341) the results of an analysis, by Dr. McNeven, of New York, of the "dry salt" from the brine-springs of Salina, a town between Liverpool and Onondago, near Lake Oneida; from which it appears to contain no less than 2.525 per cent of sulphate of potash. These results, Dr. Bigsby has had the goodness to inform me, were quoted by him from Prof. A. Eaton's Geological Survey of the District adjoining the Erie Canal, which was published in 1824 ; but they appear to have hitherto escaped the attention of chemical writers, as announcing the existence of potash in mineral salt.

Neither Dr. Henry nor Mr. Horner had occasion to institute any direct researches for potash in the salt and brine they examined. Dr. Henry, however, employed several processes for investigating the presence of alkaline sulphates, varying them according to the ascertained presence of other salts. Operating in this manner, had Dr. Henry possessed, when making his analyses, the accurate knowledge of the composition of the reagents and standards he employed, which, in com$3 \mathrm{G} 2$

mon 


\section{Mr. Brayley, Jun., on the Existence of Salts of Potash}

mon with all other chemists, he now enjoys, he could scarcely have failed to detect the presence of sulphate of potash in the varieties of salt, \&c., he examined, supposing them to have contained it. But since his estimates of the constitution of sulphate of barytes and oxalate of lime, from which his deductions were made, are both slightly in error, it cannot be satisfactorily determined, from the merely general statements given in his paper, whether he would have detected an excess of sulphuric acid or not, by the processes and estimates he actually employed. It seems most probable, however, especially if the quantity were minute, that he would not have detected an excess of this kind. For example: the Lymington salt, as may be seen by recomputing Dr. Henry's results, might have contained 1.216 parts in 1000 of sulphate of potash without his detecting it*; and since the sulphate of potash of sea-salt must be one of those saline combinations which are chiefly left in the mother-liquor, we should not expect Lymington salt to retain more than a minute quantity, like this, of sulphate of potash, out of the proportion originally existing in the seawater from which it is manufactured.

'This reasoning extends to all Dr. Henry's analyses; not only of the rock-salt and the varieties prepared from the Cheshire brine, but also of the varieties of sea-salt, and of the bitterns, as well from brine as from sea-water, and of the impure kinds separated from both fuids during the crystallization of the muriate of soda. If the varieties of salt he examined contained muriate of potash, it must be included in what Dr. Henry regards, by estimation, as "pure muriate of soda."

But Mr. Horner, in his analysis of the Droitwich brine $t$, in which he found chloride of sodium, sulphate of lime, and chloride of magnesium, found also an excess of sulphuric acid,

* Dr. Henry obtained from 1000 grains of Lymington salt " 31 grains of calcined sulphates, consisting of 19 grains of dry [anhydrous] sulphate of magnesia, and 12 grains of dry [anhydrous] sulphate of lime." "Now from the magnesian sulphate," he continues, " 38 grains of sulphate of barytes should result, and from the sulphate of lime 21 grains, the sura of which is 59. But the quantity actually obtained was 59.8. There is only, therefore, an excess of 0.8 grain of the actual above the estimated quantity; a difference much too trivial to be admitted as an indication of any sulphate with an alkaline base: and arising probably from unavoidable ervors in the experiment."-Phil. Trans. 1810 , p. 115 ; or Phil. Mag. vol. xxxvi. p. 176.

Recomputation of these results: as $60: 118:: 19: 37 \cdot 366$; and as $68: 118:: 12: 20.823$. The sum of these corrected results is 58.189 grains, which subtracted from 59.8 leaves $1 \cdot 631$ as the excess of the actual above the estimated quantity of sulphate of barytes. Now as $118: 88: 1 \cdot 631: 1 \cdot 216$, which, therefore, is the proportion of sulphate of potash in the Lymington salt that might have escaped detection.

† Trans, of Geol. Soc. Ist series, vol. ii. 
which, having previously ascertained that neither uncombined acid nor sulphate of magnesia was present, he considered as indicating the existence of sulphate of soda in the brine; without taking any means of determining whether another alkali might not be present. By recomputing the numerical results he obtained, according to our present knowledge of the constitution of the various salts in question, employing Dr. Thomson's table of equivalents, as given by Mr. R. Phillips in the Annals of Philosophy, N. S., vol. x. p. 293, this excess of sulphuric acid may be shown to amount to 3.909 grains in the quantity of entire salt (resulting from the evaporation to dryness of the brine) examined by Mr. Horner. Now it is at least quite as probable that this excess of sulphuric acid should be owing to sulphate of potash as to sulphate of soda; if indeed it be not assignable with greater. probability, to the presence of the former salt. This may be seen from the following statement.

On recomputing Mr. Horner's results, it will be found that the 431.860 grs. of entire salt analysed, contain, of

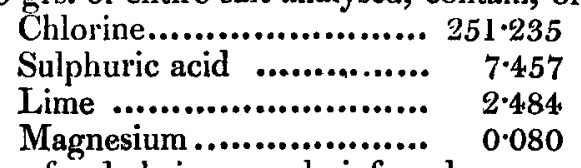

the quantity of soda being merely inferred, as usual.

The magnesium is evidently in the state of chloride in the salt: 0.080 of magnesium combine with 0.240 of chlorine, becoming 0.320 of chloride of magnesium. This leaves 250.995 of chlorine, which unite with 167.305 of sodium to become 418.300 of chloride of sodium*.

Again : $2 \cdot 484$ of lime require for their conversion into sulphate of lime 3.548 of sulphuric acid, forming $6 \cdot 032$ of the sulphate.

We thus find that the proximate constituents of this entire salt, neglecting the excess of sulphuric acid, are

$$
\begin{array}{rr}
\text { Chloride of sodium ................ } & 418 \cdot 300 \\
\hline \text { Sulphate of lime...................... } & \frac{0 \cdot 320}{6 \cdot 032} \\
\text { Deficiency } \ldots . . . . & \frac{7 \cdot 24 \cdot 652}{431 \cdot 860} \\
\hline
\end{array}
$$

- It would have been inconsistent with the truth of chemical science, if, in recomputing Mr. Horner's analysis, the terms and appropriate numbers for chlorine, magnesium and sodium, had not been substituted for those of muriatic acid, magnesia, and soda. But no opinion is meant to be expressed as to the actual state of combination in which the elements of the muriatic salts exist in the brine. The true state of the general question on this subject appears to be, that some chlorides are converted into muriates by solution in water, while others, when in solution, retain the chloridic forn. 


\section{Mr. Brayley, Jun., on the Existence of Salts of Potash}

Towards this deficiency we have the 3.909 of sulphuric acid, yet unappropriated. If we suppose this to be combined with potash, we shall have 8.599 of sulphate of potash, being no more than 1.391 in excess, on the entire quantity of salt analysed. If we suppose it to be combined with soda, we shall have 7.081 of sulphate of soda, which is only 0.127 in defect, on the entire quantity.

Mr. Horner quotes Nicholas, Hassenfratz, and Montigny, as stating sulphate of soda to be a constituent part of all the (foreign) brine-springs they examined. But they had no rea. son to suspect the presence of potash; and when we consider that from the state of chemical science when they operated, they must have employed very defective methods of analysis, it is quite as probable that Nicholas and Hassenfratz attributed to sulphate of soda the acid really due to sulphate of potash, as that the former salt existed in the brines analysed by them; while Montigny, whose analysis was made so far back as 1762 , po doubt obtained his sulphate of soda, by the action upon each other of the saline constituents of the brine during evaporation.

If the Droitwich brine contains muriate of potash, it must be included in what $\mathrm{Mr}$. Horner estimates as muriate of soda.

In the Phil. Mag, vol. lxiv. p. 74, will be found the results of Mr. G. Chilton's analyses of some of the principal brinesprings in the State of New York, with an account of the process he employed. He neither mentions potash nor any alkaline sulphate; and had the latter existed in the brine, his process would have enabled him to detect it, if he employed correct equivalents; which, from the date of his analysis (1824), it is to be presumed he would. Muriate of potash he would not have detected*. In Dr. Beck's analysis of the entire salt from Salina brine, quoted in Mr. S. Smith's notice of the saltsprings at that place (Silliman's Journal, vol. xv. p. 11), neither potash nor any alkaline sulphate is mentioned. The mode of analysis emplayed is not quoted. How far the details of Klaproth's analyses of brine-springs may throw light on this subject, I am not aware.

To complete this summary of our present knowledge on this interesting subject of chemical inquiry, which has been drawn up with the view of showing the necessity of instituting fresh researches upon it, I add the following notices.

Dr. Wollaston detected traces of potash in the nearly satu-

* It is a remarkable circumstance, if Mr. Chilton's analysis be correct, that the springs he examined are in the same district as those of Salina, and rise under precisely sinilar geological circumstances. 
rated water, in many respects strongly resembling that of the Dead Sea, of the Lake Ourmia, or Lake of Shahee, in Persia, Phil. Trans. 1819, p. 194 .

In the Phil. Mag. and Annals, N. S. vol. ii. p. 232, will be found the results of C. G. Gmelin's analysis of the water of the Dead Sea, which he states to contain 1.6738 per cent of chloride of potassium, without mentioning sulphate of potash.

A train of research instituted for the purpose of ascertaining whether all the saline constituents of sea-water are to be found, and in the same proportions, respectively, in rock-salt and in brine-springs, would be of great interest in a geological point of view; since, although obvious inference and many circumstances attending the deposits of rock-salt refer their origin to the ocean, yet there are difficulties affecting the most plausible theories of their formation, which a minute comparison of the constituents of rock-salt, \&c., with those of sea-water, would probably tend to remove.

The quantity of sulphate of potash which Dr. Wollaston found in sea-water, by an approximative method, is in the proportion of $2 \cdot 163$ per cent of the total quantity of saline matter contained in it*. Now this quantity differs only 0.362 , in defect, from that assigned by Dr: $M^{c}$ Neven to the entire salt of Salina; and it differs only 0.172 , in excess, from the proportion of the same salt in the evaporated Droitwich brine, assuming the excess of sulphuric acid detected by Mr. Horner to exist in it in combination with potash. This near accordance, perhaps, may be regarded as confirmatory of the truth of that assumption.

It is probable that the potash in sea-water does not arise exclusively from the source suggested by Dr. Wollaston, since that alkali is a constituent, and in no inconsiderable proportion, of the oldest rocks. But even if we should prefer to ascribe its presence in sea-water wholly to the decay of plants, still there is no difficulty in conceiving its introduction, by the same means, into the waters of the primæval ocean, from which, by whatever operation of nature, and whatever changes may subsequently have been induced, the beds of rock-salt must originally have been deposited. For we know that land and

* Dr. Wollaston found sea-water of the specific gravity of 1026.22 to contain about $\frac{1}{200}$ of sulphate of potash. (Phil. Trans. 1819, p. 201.) And from Dr. Marcet's experiments (Ib. p. 202) it will be found that sea-water of this density must contain 19.28 grains of saline matter in 500 of the water.

Now $\frac{500}{2200}=0.417$ very nearly, which is the quantity of sulphate of potash contained in 500 grains of sea-water, or in the 19:28 grains of saline matter which they hold in solution. Therefore as $19 \cdot 28: 0 \cdot 417:: 100: 2 \cdot 163$.

fresh- 
fresh-water plants, of several orders, existed in abundance, prior to the formation of the new-red-sandstone strata, in which the beds of salt occur.

On reviewing the chemical history of these subjects, it appears, in conclusion, that a series of new and exact researches on the contents of sea-water and of the rock-salt and brine of all countries, is now required by science. Subordinate to this would be required an investigation of the interesting points involved in the following : viz. the limits of compatibility with each other of the various salts concerned, their mutual action during the evaporation of solutions containing them, and the state of combination in which the elements of the salts obtained from sea-water actually exist in that fluid. The last Jabours of Dr. Murray (Trans. Roy. Soc. Edin, vol. viii.) and Dr. Marcet, in particular, especially so far as relates to the second of these subjects, require to be examined and reconciled.

16, St. James's-street, Clerkenwell : May 5, 1829.

LXI. On the Specific Gravities of Compound Bodies. By the Rev. J. B. EмметT.

To the Editors of the Philosophical Magazine and Annals. Gentlemen,

HAVING had occasion to institute some inquiries into the specific gravity of certain compounds, I have found that some highly erroneous tables computed by Hassenfratz are generally adopted. The errors arise from two sources. Where substances/which are soluble in water are concerned, a known quantity was accurately weighed in air, and afterwards in a bottle fllled with mercury. It is well known that on account of the air contained in poraus bodies, such as lime, hydrate of lime, magnesie, calcined alum or borax, and small crystals, as well as on aocount of capillary action, mercury does not enter into the pores; and consequently the resulting specific gravity is not that of the solid matter, but that of the volume made up of the mass of solid matter and of the pores or interstices together. The error is often very great: for example, Hassenfratz assigns the specific gravity 0.4229 to calcined alum, although the powder sinks rapidly in water: also, the specific gravity of the powder consisting of lime 2 and water 1 , he gives 0.8983 ; yet this powder sinks in water. The specific gravity of lime must exceed his estimate $1 \cdot 4558$; for the specific gravity of its carbonate is $2 \cdot 7$; it consists of 26.5 lime and 20.7 carbonic acid; this acid escapes during calcination, yet the volume is but little altered; hence in this porous state its gravity will be about 1.5 : in this state it mechanically absorbs a large 